\section{POS0791 DOSE-DEPENDENT RELATIONSHIP BETWEEN HISTORY OF DENTAL CARIES AND INCREASED RISK OF NEWLY-ONSET SYSTEMIC LUPUS ERYTHEMATOSUS: A NATIONWIDE POPULATION- BASED COHORT STUDY}

K. S. K. Ma ${ }^{1} .^{1}$ National Taiwan University, Taipei, Taiwan, ROC, Department of Life Science, Taipei, Taiwan, Republic of China

Background: The relationship between oral bacterial invasion caused by periodontal pathogens and risk of systemic lupus erythematosus (SLE) has been identified. However, there is a lack of knowledge on the relationship between carious lesions and risk of SLE, as well as longitudinal studies on the effect of restorative materials on SLE.

Objectives: This study investigated whether patients with history of dental caries are associated with an increased risk of newly-onset systemic lupus erythematosus (SLE)

Methods: A total of 541,461 carious patients and 258,918 controls without carious teeth were enrolled between 1997 and 2013 from the National Health Insurance Research Database. Subgroup analyses were conducted based on restorative materials included amalgam, resins or both. Cumulative incidences and hazard ratios (HRs) of developing SLE were derived after adjusting for age, gender, comorbidities and co-medications in a multivariable model.

Results: The risk of SLE was significantly higher in carious patients $(H R=1.984$, $95 \%=1.652-2.382$ ) compared to controls. Dose-dependent relationship between caries and risk of SLE was identified. The risks of SLE were higher among those who had over 11 dental visits ( $\mathrm{HR}=2.525,95 \% \mathrm{C} . \mathrm{I}=1.859-3.429)$, followed by those with 3-10 dental visits ( $\mathrm{HR}=1.863,95 \% \mathrm{C} . \mathrm{I}=1.356-2.543)$, then those with $1-2$ visits, and were higher among those who had over 5 carious teeth extractions $(\mathrm{HR}=1.877,95 \% \mathrm{C} . \mathrm{I}=1.186-2.970)$, followed by those with $1-4$ carious teeth extractions $(\mathrm{HR}=1.363,95 \% \mathrm{Cl}=1.167-1.593)$, then those without extraction. The risk of SLE among different restorative materials, including amalgam or resins, for caries management, were not significantly different.

Conclusion: Patients with caries were associated with higher SLE risks. The relationship between caries and risk of SLE was dose-dependent, regardless of used restorative materials.

Disclosure of Interests: None declared

DOI: 10.1136/annrheumdis-2021-eular.3945

\section{POS0792 BASELINE FACTORS ASSOCIATED WITH LUPUS FLARES: A POST-HOC ANALYSIS OF PATIENTS WITH MODERATE TO SEVERE ACTIVE SYSTEMIC LUPUS ERYTHEMATOSUS ENROLLED IN A 48 WEEK PHASE II RANDOMIZED CLINICAL TRIAL}

L. Lindsay ${ }^{1}$, H. A. Mao ${ }^{2}$, J. E. Cheng ${ }^{2}$, C. Y. Chuo ${ }^{3}$, N. Jones ${ }^{4}$, M. D. Cascino ${ }^{4}$ K. Tuckwell ${ }^{4}{ }^{1}$ Genentech, Inc., Personalized Healthcare Data Science, South San Francisco, United States of America; ${ }^{2}$ Hoffmann-La Roche Limited, Product Development Biometrics, Mississauga, Canada; ${ }^{3}$ Genentech, Inc., Personalized Healthcare Analytics, South San Francisco, United States of America; ${ }^{4}$ Genentech, Inc., Product Development Clinical Science, South San Francisco, United States of America

Background: Systemic lupus erythematosus (SLE) is a chronic disease characterized by periodic flares associated with poor outcomes and subsequent organ damage (1-2). Flare prevention is important for optimal patient management and development of effective therapies.

Objectives: To identify patient-level factors associated with flares among patients with moderate/severe SLE.

Methods: We conducted a post-hoc analysis of 260 patients with active, autoantibody+ SLE enrolled in a phase II randomized clinical trial (Fenebrutinib) (3). The relationship between baseline demographic (age, gender, ethnicity, BMI), region (US/EU, outside US/EU), disease severity (PGA, SLEDAI-2K, BILAG domain involvement), disease duration, serologic markers (C3, C4, ANA, anti-dsDNA Ab, anti-Smith $A b$ ), treatment arm, standard of care (SOC) and flares (BILAG and $\mathrm{SFI}$ ) over 48 wks was assessed by survival analysis and multiple Cox Proportional Hazard models. We examined concordance between BILAG and SFI flares using Cohen's Kappa Index.

Results: The overall rate of flare was low ( $n=37$ SFI flare, $n=25$ BILAG flare). Median time to first flare was 8 wks for SFI flares compared to 12 wks for BILAG flares. There was no difference in flare rate by treatment arm. Cumulative flare hazard increased over time. Concordance between SFI and BILAG flares was 0.14. Multivariable analyses identified a higher flare rate for both $\mathrm{SFI}$ and BILAG-defined flares in patients with severe disease at baseline (PGA >1.7, SLEDAI- $2 \mathrm{~K} \geq 10$ ) and $<7$ y disease duration.

Flares were more common in patients ANA, anti-dsDNA and anti-Smith + at baseline compared to patients with $<3+$ markers $(p<.001)$. Furthermore, anti-dsDNA $(p=.03)$ and/or anti-Smith $(p=.001)$ positivity at baseline were better indicators of higher flare rate compared to ANA $(p=0.5)$. Low baseline complement level (C3 and C4) was associated with a higher flare rate $(p=.03$ and $p=.03$ respectively)

Patients from non-US/EU regions had a higher flare rate compared to patients from the US/EU, despite receiving more frequent SOC therapy and higher baseline corticosteroid doses $(\geq 10 \mathrm{mg} / \mathrm{d})$. Overall, flare-free probability was comparable at 48 wks regardless of baseline corticosteroid dose but patients receiving $<10 \mathrm{mg} / \mathrm{d}$ had a median time to flare of 4 vs 24 wks for those receiving $\geq 10 \mathrm{mg} / \mathrm{d}$ $(\mathrm{p}=.004)$.

Conclusion: In this study, flares were more common among patients with more severe disease, shorter disease duration, multiple serologic markers, were from outside the US/EU, and received lower steroid doses at baseline.

\section{REFERENCES:}

[1] Fernandez D and Kirou KA. Curr Rheumatol Rep 2016 18:14.

[2] Stoll T, et al. Rheum (Oxford) 2004 43(8):1039-44.

[3] Isenberg D, et al. Arth Rheum 201971 suppl 10.

\begin{tabular}{|c|c|c|c|c|}
\hline \multirow[t]{2}{*}{ Baseline Factors (\%) } & \multirow[t]{2}{*}{ No Flare $n=206$} & \multicolumn{3}{|c|}{ Flare } \\
\hline & & BILAG $n=25$ & SFI $n=37$ & $\begin{array}{l}\text { BILAG and } \\
\text { SFI } n=8\end{array}$ \\
\hline Age (mean (SD)) & $41.8(12)$ & $35.2(9)$ & $40.4(10)$ & $34.9(8)$ \\
\hline Female & 199 (97) & $24(96)$ & $35(95)$ & $7(88)$ \\
\hline PGA (mean (SD)) & $1.7(0.5)$ & $1.7(0.4)$ & $1.9(0.5)$ & $1.7(0.6)$ \\
\hline BILAG A/B any domain & $197(96)$ & $23(92)$ & 35 (95) & $7(88)$ \\
\hline SLEDAI $2 \mathrm{~K}>=10$ & $87(42)$ & $18(72)$ & $17(46)$ & $4(50)$ \\
\hline $\begin{array}{l}\text { Disease duration (y) (mean } \\
\quad(S D) \text { ) }\end{array}$ & $9.4(7)$ & $5.3(4)$ & $6.6(6)$ & $2.9(3)$ \\
\hline $\mathrm{ANA}+$ & 203 (99) & $24(96)$ & $35(95)$ & $8(100)$ \\
\hline anti-dsDNA + & $102(50)$ & $18(72)$ & $21(57)$ & $5(63)$ \\
\hline anti-Smith + & 45 (22) & $13(52)$ & 12 (32) & $4(50)$ \\
\hline Low C3 & $57(28)$ & $12(48)$ & $13(35)$ & $3(38)$ \\
\hline Low C4 & $26(13)$ & $7(28)$ & $4(11)$ & $1(13)$ \\
\hline Non US/EU & $157(76)$ & $21(84)$ & $32(87)$ & $8(100)$ \\
\hline Corticosteroid & $130(63)$ & $14(56)$ & $21(57)$ & $5(63)$ \\
\hline$\geq 10 \mathrm{mg} / \mathrm{d}$ & $80(39)$ & $9(36)$ & $14(38)$ & $4(50)$ \\
\hline Immunosuppressant & $74(36)$ & $12(48)$ & $15(41)$ & $3(38)$ \\
\hline Antimalarial & $135(66)$ & $14(56)$ & $21(57)$ & $5(63)$ \\
\hline
\end{tabular}

Notes: included patients 18-75 y; 1 + serologic marker of SLE; SLEDAI-2K >=8, PGA>=1; $1+$ oral SOC treatment

$\mathrm{SFI}=\mathrm{SELENA}-\mathrm{SLEDAI}$ Flare Index

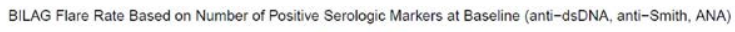

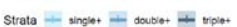
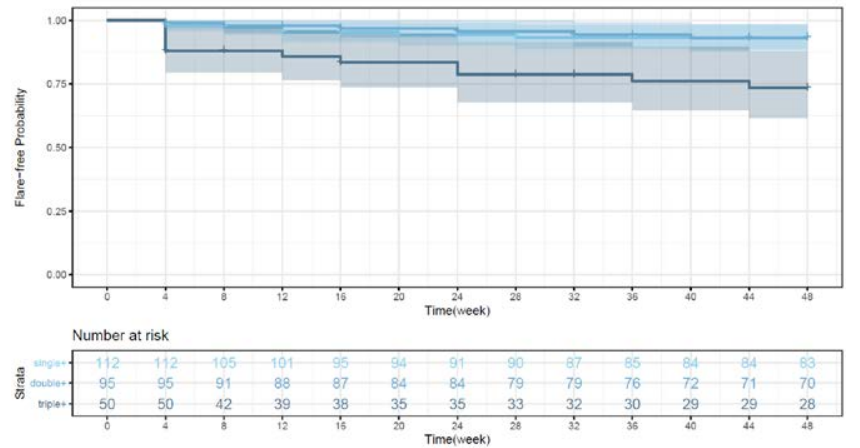

Disclosure of Interests: Lisa Lindsay Shareholder of: Employee of Genentech, Inc., Employee of: Employee of Genentech, Inc., Huiyan (Ashley) Mao Shareholder of: Employee of Hoffmann-La Roche Limited, Employee of: Employee of Hoffmann-La Roche Limited, Ji (Emmy) Cheng Shareholder of: Employee of Hoffmann-La Roche Limited, Employee of: Employee of Hoffmann-La Roche Limited, Ching-Yi Chuo Shareholder of: Employee of Genentech, Inc., Employee of: Employee of Genentech, Inc., Nicholas Jones Shareholder of: Employee of Genentech, Inc., Employee of: Employee of Genentech, Inc., Matthew D. Cascino Shareholder of: Employee of Genentech, Inc., Employee of: Employee of Genentech, Inc., Katie Tuckwell Shareholder of: Employee of Genentech, Inc., Employee of: Employee of Genentech, Inc.

DOI: 10.1136/annrheumdis-2021-eular. 4042

\section{POS0793 \\ PREDICTORS OF END STAGE RENAL DISEASE IN THE} RENAL BIOPSY PROVEN LUPUS NEPHRITIS

E. Duran ${ }^{1}$, T. Yıldıım² ${ }^{2}$ U. Kalyoncu ${ }^{1}$, A. Taghiyeva ${ }^{3}$, E. Arzu Sağlam ${ }^{4}$, M. Üner ${ }^{4}$, E. Bilgin ${ }^{1}$, J. Jabrayilov' ${ }^{2}$, E. C. Bolek ${ }^{1}$, C. Önal ${ }^{2}$, B. Farisoğulları ${ }^{1}$, N. S. Koç ${ }^{2}$ G. K. Yardımc1 ${ }^{1}$, S. Girgin ${ }^{2}$, G. Ayan ${ }^{1}$, Z. Özsoy ${ }^{1}$, G. Sandal Uzun ${ }^{1}$, L. Kılıc ${ }^{1}$, S.. R. Yılmaz², A. Akdoğan', Ş. A. Bilgen ${ }^{1}$, O. Karadag' ${ }^{1}$ S. Kiraz ${ }^{1}$, B. Altun², 